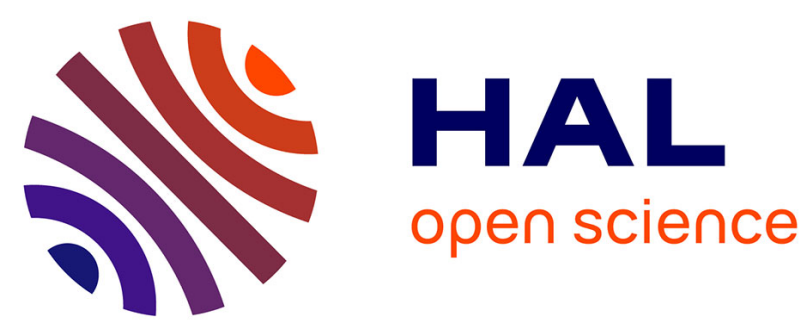

\title{
Divertor power loads and scrape off layer width in the large aspect ratio full tungsten tokamak WEST
}

\author{
J. Gaspar, Yann Corre, Clarisse Bourdelle, S. Brezinsek, J. Bucalossi, N.
}

Chanet, R. Dejarnac, N. Fedorczak, M. Firdaouss, J-L. Gardarein, et al.

\section{- To cite this version:}

J. Gaspar, Yann Corre, Clarisse Bourdelle, S. Brezinsek, J. Bucalossi, et al.. Divertor power loads and scrape off layer width in the large aspect ratio full tungsten tokamak WEST. IAEA FEC 2021 - The 28th IAEA Fusion Energy Conference, May 2021, Nice (Virtual conference), France. cea-03252519

\section{HAL Id: cea-03252519 \\ https://hal-cea.archives-ouvertes.fr/cea-03252519}

Submitted on 7 Jun 2021

HAL is a multi-disciplinary open access archive for the deposit and dissemination of scientific research documents, whether they are published or not. The documents may come from teaching and research institutions in France or abroad, or from public or private research centers.
L'archive ouverte pluridisciplinaire HAL, est destinée au dépôt et à la diffusion de documents scientifiques de niveau recherche, publiés ou non, émanant des établissements d'enseignement et de recherche français ou étrangers, des laboratoires publics ou privés. 


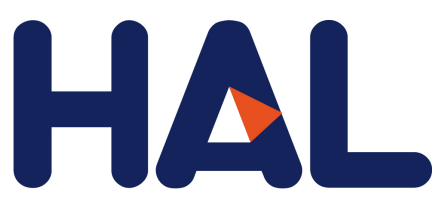

archives-ouvertes

\section{DIVERTOR POWER LOADS AND SCRAPE OFF LAYER WIDTH IN THE LARGE ASPECT RATIO FULL TUNGSTEN TOKAMAK WEST}

J Gaspar, Y Corre, C Bourdelle, S Brezinsek, J Bucalossi, N Chanet, R Dejarnac D, N Fedorczak, M Firdaouss, J-L Gardarein, et al.

\section{To cite this version:}

J Gaspar, Y Corre, C Bourdelle, S Brezinsek, J Bucalossi, et al.. DIVERTOR POWER LOADS AND SCRAPE OFF LAYER WIDTH IN THE LARGE ASPECT RATIO FULL TUNGSTEN TOKAMAK WEST. IAEA FEC 2021, May 2021, E-CONFERENCE NICE, France. cea-03252559

HAL Id: cea-03252559

https://hal-cea.archives-ouvertes.fr/cea-03252559

Submitted on 7 Jun 2021

HAL is a multi-disciplinary open access archive for the deposit and dissemination of scientific research documents, whether they are published or not. The documents may come from teaching and research institutions in France or abroad, or from public or private research centers.
L'archive ouverte pluridisciplinaire HAL, est destinée au dépôt et à la diffusion de documents scientifiques de niveau recherche, publiés ou non, émanant des établissements d'enseignement et de recherche français ou étrangers, des laboratoires publics ou privés. 


\title{
DIVERTOR POWER LOADS AND SCRAPE OFF LAYER WIDTH IN THE LARGE ASPECT RATIO FULL TUNGSTEN TOKAMAK WEST
}

\author{
J. GASPAR \\ a Aix Marseille Univ, CNRS, IUSTI, Marseille, France \\ Email: jonathan.gaspar@univ-amu.fr
}

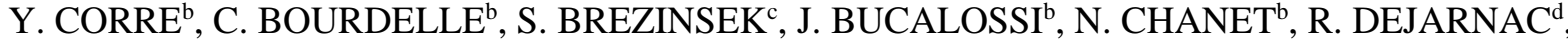 \\ N. FEDORCZAK ${ }^{\mathrm{b}}$, M. FIRDAOUSS ${ }^{\mathrm{b}}$, J-L. GARDAREIN ${ }^{\mathrm{a}}$, J. P. GUNN ${ }^{\mathrm{b}}$, G. LAFFONT ${ }^{\mathrm{e}}$, T.

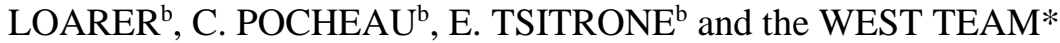 \\ ${ }^{b}$ CEA, Institute for Research on Fusion by Magnetic confinement, 13108 Saint-Paul-Lez-Durance, France \\ ${ }^{c}$ FZ Jülich, Institut für Energie - und Klimaforschung - Plasmaphysik, TEC, 52425 Jülich, Germany \\ ${ }^{d}$ Institute of Plasma Physics, Czech Academy of Sciences, Prague, Czech Republic \\ e CEA, LIST, Gif-sur-Yvette Cedex 91191, France \\ * See http://west.cea.fr/WESTteam
}

\begin{abstract}
WEST is a full $\mathrm{W}$ tokamak with an extensive set of diagnostics for heat load measurements especially in the lower divertor. It is composed by infrared (IR) thermography, thermal measurement with thermocouples (TC) and fiber Bragg grating (FBG) embedded few mm below the surface and flush mounted Langmuir probes (LP). A large database including different magnetic equilibrium and input power is investigated to compare the heat load pattern (location, amplitude of the peak and heat flux decay length) on the inner and outer strike point regions as function of the continuous progress achieved in WEST : from the first ohmic diverted plasma (obtained during the second experimental campaign C2 in 2018) up to the high power (up to $8 \mathrm{MW}$ total injected) and high energy (up to $90 \mathrm{MJ}$ injected energy in lower single null configuration) steady state experiments performed in the last experimental campaign (C4 in 2019). Concerning the peak location, a good agreement $(<1 \mathrm{~cm})$ is obtained between thermal inversions and flush-mounted LP measurements. The peak heat flux from the whole set of diagnostics is in good agreement and mainly in the $\pm 20 \%$ range, while the heat flux decay length reported on the target shows significant discrepancy between diagnostics and location in the machine ( $\pm 40 \%$ range). Despite such discrepancy, heat flux decay length at target is found to scale mainly with the magnetic flux expansion through the variation of the X-point height, as expected. The improved plasma performances achieved during C4 enabled to reach significant heat load in the divertor, up to $6 \mathrm{MW} / \mathrm{m}^{2}$ with $4 \mathrm{MW}$ of additional heating power showing the capability to reach the ITER relevant heat load $\left(10 \mathrm{MW} / \mathrm{m}^{2}\right.$ steady state) with about $7 \mathrm{MW}$ of additional power in L-mode discharge. The heat load distribution is clearly asymmetric with a $3 / 4$ and $1 / 4$ distribution on the outer and inner strike point region respectively for the parallel heat flux close to the $2 / 3-1 / 3$ commonly observed in forward-B divertor configuration.
\end{abstract}

\section{INTRODUCTION}

One of the main goals of WEST is the assessment of power handling capabilities and lifetime of tungsten divertor components under high heat flux and high fluence operation in a full $\mathrm{W}$ tokamak environment [1]. During the first four experimental campaigns (named C1 to C4), WEST operated with a mix of actively cooled ITER like tungsten plasma facing units and inertial tungsten coated graphite components [2]. The preliminary step towards testing the tungsten ITER like components under ITER relevant heat flux $\left(10 \mathrm{MW} / \mathrm{m}^{2}\right.$ in steady state), is to characterize the heat flux deposition pattern in terms of intensity and decay length. For this purpose, a set of complementary diagnostics allowed characterizing properties of the heat loads on the lower divertor: arrays of embedded thermocouples (TC) and Fiber Bragg Gratings (FBG) sensors [3], infra-red thermography (IR) [4] and arrays of flush-mounted Langmuir probes (LP) [5]. First heat flux calculations were performed during early diverted ohmic plasma experiments as depicted in [6]. First comparison between FBG and IR calculations only is reported in [7]. On this basis, the study has been extended with TC and LP measurements available during each campaign. The heat flux database is built as a function of the continuous progress achieved in WEST : from the first ohmic diverted plasma (obtained during the second experimental campaign C2 in 2018) up to the high power (up to 8 MW total injected power during $4 \mathrm{~s}$ ) and high energy (up to $90 \mathrm{MJ}$ total injected energy in lower single null configuration) steady state L-mode plasma experiments performed in the last experimental campaign (C4 in 2019) [2]. We report on the heat load pattern, position of the strike point, peak heat flux and heat flux decay length, on both the outer and inner strike point regions, as a function of the plasma parameters, heating power $\left(\mathrm{P}_{\mathrm{tot}}\right)$, divertor power $\left(\mathrm{P}_{\mathrm{div}}=\mathrm{P}_{\mathrm{tot}}-\mathrm{P}_{\mathrm{rad}}\right)$, plasma current $\left(\mathrm{I}_{\mathrm{p}}\right)$ and divertor magnetic equilibrium (far and close $\mathrm{X}$-point) for deuterium and helium plasmas. It includes heat flux calculation for $228 \mathrm{~L}$-mode plasma experiments achieving at least four seconds of steady state plasma to get significant heating and accurate heat flux calculation from all heat load diagnostics. 
The heat load diagnostics set-up as well as the processing methodology are presented in section 2. Section 3 focus on selected discharges from the campaign $\mathrm{C} 4$ where all diagnostics were simultaneously available allowing crosscheck between them on estimated peak heat flux and heat flux distribution properties (peak location and decay length) on the outer strike point region. Finally, the last section extends the database from the first diverted deuterium plasma during campaign $\mathrm{C} 2$ up to the last helium discharge of the campaign $\mathrm{C} 4$, the evolution of the peak heat flux over the campaigns as well of the heat load asymmetry are discussed on both strike point regions (outer/inner).

\section{HEAT LOAD DIAGNOSTICS SET-UP AND HEAT FLUX DATABASE}

The WEST divertor consists of 12 independent toroidal sectors of $30^{\circ}$ each composed of 38 plasma facing units. During the WEST phase 1, a mix of ITER-like actively cooled components (bulk W) [8] and non-actively cooled $\mathrm{W}$-coated graphite components is used [9]. The W-coated graphite is divided in two separate components, one in the low field side (LFS/outer) and one in the high field side (HFS/inner). The WEST lower divertor is monitored by a set of complementary diagnostics allowed characterizing properties of heat loads on the lower divertor: 20 embedded TCs located at 7.5mm below the surface [10], 4 FBGs [3] embedded at 3.5 and $7 \mathrm{~mm}$ below the surface, IR thermography [4] and two arrays of 29 flush-mounted LPs [5].The diagnostic are spread over the 12 divertor sectors keeping symmetric toroidal location of the sensors regarding the magnetic field toroidal modulation (ripple effect). A poloidal cross section of the WEST device with two magnetic configurations with a separatix located at $R_{\text {ext }}=2.93 \mathrm{~m}$ and $3 \mathrm{~m}$ is shown in fig $1 \mathrm{a}$.

The WEST IR system used in this analysis consists of several different actively cooled endoscope located at the top of the chamber monitoring the lower divertor. The IR cameras are equipped with a filter at the wavelength 3.9 $\pm 0.1 \mu \mathrm{m}$, a frame size of $640 \times 512$ pixels. The projected pixel size is about $2.5 \mathrm{~mm} / \mathrm{pixel}$ for the reported PFC studies of this paper. One IR camera is monitoring a sector also equipped with 16 TCs including 2 PFCs with 4 TCs and the flush-mounted LPs as illustrated in fig $1 \mathrm{~b}$ ). The IR system is calibrated and translate the collected radiance into blackbody surface temperature. The deposited heat flux is estimated from these data using the TEDDY code [11]. The main limitations in this inversion can result from both the reflected radiance at low surface temperature [12] and the non-uniform emissivity observed on the PFCs [13]. To overcome these difficulties a procedure has been implemented in the TEDDY code to determine the effective emissivity and background reflections (supposed constant during the discharge) using the IR measurements just prior the plasma and the TC measurements [11]. The main improvement (remaining to be done) for the IR processing in TEDDY is to implement the variation of the emissivity with the PFC temperature, for this purpose post-mortem measurement is foreseen to investigate the emissivity dependency in area presenting higher emissivity than $\mathrm{W}$ to complement the previous measurement performed on virgin sample [14].

The embedded measurements are used to solve an inverse heat conduction problem. This problem consists in the determination of the surface heat flux $(\phi)$ minimizing the discrepancy between the output of a heat conduction problem giving the PFC bulk temperature and the temperature measurements provided by the PFCs with 4 TCs or with the 11 FBGs. The conjugate gradient method combined with the adjoint state is the optimization process used to solve the inverse problem [6]. As the inverse problem is ill-posed the inversion algorithm is constrained by imposing a shape function to the deposited heat flux given by Eq. 1 [15].

$$
\phi(x, t)=\phi_{M}(t) \exp \left[\left(\frac{s^{t}}{2 \lambda_{q}^{t}}\right)^{2}-\frac{s-s_{0}}{\lambda_{q}^{t}}\right] \times \operatorname{erfc}\left(\frac{s^{t}}{2 \lambda_{q}^{t}}-\frac{s-s_{0}}{s^{t}}\right)+\phi_{B G}(t)
$$

From this shape, five parameters can be estimated: the background and the amplitude of the heat flux evolving in time and three parameters supposed constant during pulses with steady state plasma (fixed magnetic equilibrium, plasma density, plasma current, injected power), the heat flux decay length at the target $\left(\lambda_{q}^{t}\right)$, the strike point location $\left(s_{0}\right)$, the Gaussian spreading factor $\left(S^{t}\right)$ and $s$ is the curvilinear length along the PFU. In this study the spreading factor is supposed to be equal to $5 \mathrm{~mm}$ which is the usually measured value from the IR inversion. Here we will focus on three arrays of 4 TCs embedded in two PFCs on the outer side (low field side) called $\mathrm{TC}_{\mathrm{Q} 6 \mathrm{~A}}$ and $\mathrm{TC}_{\mathrm{Q} 1 \mathrm{~A}}$ (subscript corresponding to the divertor sector) and one $\mathrm{PFC}$ on the inner side (high field side) also installed in the sector Q6A. The 2 PFCs (outer/inner) with 4 TCs from the sector Q6A stand next to the two arrays of 29 flush mounted LPs [5] and these tiles are located at the toroidal positions where the ripple modulation of the incidence angle of magnetic field lines provides the maximum deposited heat flux in each region. Each array starts from the inner side and go to the outer side with a probe spacing of $12.5 \mathrm{~mm}$. During the discharges the probes voltages are swept during $1 \mathrm{~ms}$ every $4 \mathrm{~ms}$, then the collected I-V characteristics are processed to provide the local parallel ion current density $\left(\mathrm{J}_{/ / \mathrm{i}}\right)$ and $\mathrm{T}_{\mathrm{e}}$. Local density and parallel heat flux are then estimated assuming $T_{e}=T_{i}(\gamma=7)$. 

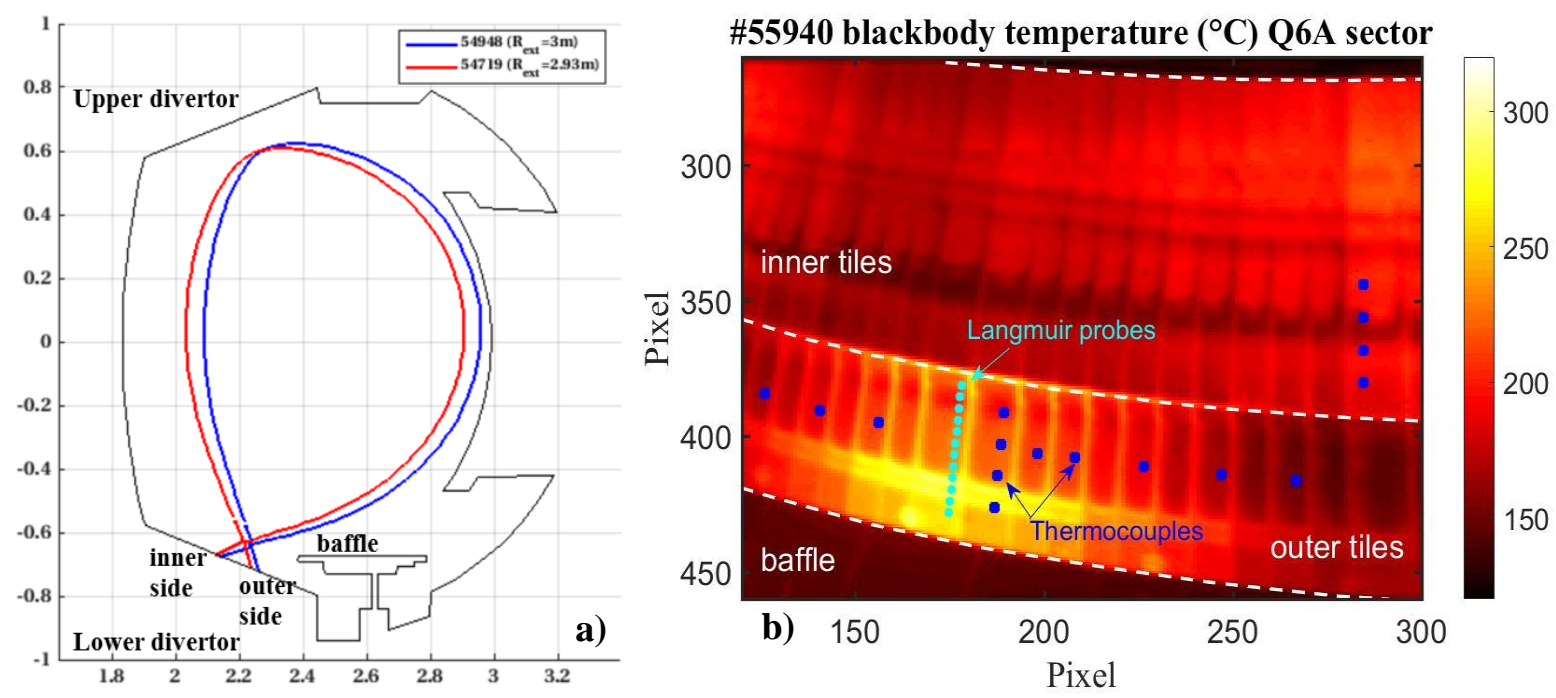

FIG. 1. a) Poloidal magnetic field configuration with $R_{\text {ext }}=2.93 \mathrm{~m}$ and $3 \mathrm{~m}$. $\left.\boldsymbol{b}\right)$ Top view of the lower divertor instrumented with 16 TCs (blue squares) and the 12 LPs (cyan circle) used in this study.

\section{HEAT LOAD DIAGNOSTICS COMPARISON}

The comparison of the estimated heat fluxes by the heat load diagnostics focus on the discharges from the campaign C4 (2019). The discharge database of the first cross-check analysis [7] has been extended from 114 discharges to 165, most importantly the TC inversions from the 2 tiles instrumented with 4 TCs (Q6A and Q1A) have been added as well as the LP measurements (Q6A) for 63 discharges corresponding to the last part of the campaign. To compare the shape of the heat profiles obtained from the different diagnostics, the estimated heat fluxes from the IR and LP measurements are averaged over 1s during the stationary phase of the discharges and the profiles are fitted with the same shape function (Eq 1) used for the TCs and FBG inversions. As 2 sets of TCs will be used for more clarity and we will refer to the TC located on the sector Q6A and Q1A with the name $\mathrm{TC}_{\mathrm{Q} 6 \mathrm{~A}}$ and $\mathrm{TC}_{\mathrm{Q} 1 \mathrm{~A}}$, respectively. This database includes attached L-mode Lower Single Null (LSN) discharges with heating powers from 1 to $8 \mathrm{MW}$ (combining up to $4.8 \mathrm{MW}$ of lower hybrid current drive and up to $3.1 \mathrm{MW}$ of ion cyclotron resonance heating) with magnetic fields $B_{T}$ from 3.5 to $3.7 \mathrm{~T}$ and plasma current $I_{p}$ from 300 to $700 \mathrm{kA}$ (corresponding to edge safety factor $\mathrm{q}_{95}$ from 7.8 to 3.2 respectively). Here we focus on the outer strike point region as the inner region shows features on the IR and LP measurement that are not fully understood yet.

Fig 2a) compares the peak heat fluxes estimated from the TCs/FBG and LP measurements to the heat fluxes derived from IR thermography. An overall agreement is found with a main dispersion of $20 \%$ up to $30 \%$ for a part of the database, as depicted in [7]. This comparison shows that at the maximal heat flux location, where the surface temperature is maximal and the IR reflection influence minimal, a very good agreement is observed between the IR inversion, the embedded TCs/FBG and the LP measurements. Fig $2 \mathrm{~b}$ ) shows the estimated strike point position $\mathrm{s}_{0}$ with the edge diagnostics using the equation 1 describing the heat flux distribution and the magnetic reconstruction performed by the code NICE [16] using magnetic measurements and interfero-polarimetry constrains. All the diagnostics agree with a dispersion of few $\mathrm{mm}$ which is lower than the sensors spacing (12.5 $\mathrm{mm}$ for FBGs and LPs and $37.5 \mathrm{~mm}$ for TCs) and equivalent to the IR spatial resolution (about $2.5 \mathrm{~mm}$ ) The main shift is between the estimated $\mathrm{s}_{0}$ and the reconstructed $\mathrm{s}_{0}$ from the code NICE with a shift between 10 and $20 \mathrm{~mm}$ and seems higher for the He discharges. Only LP measurements seem to exhibit a dependency with the magnetic configuration with some points in agreement with NICE. The shift is such as the reconstructed $\mathrm{s}_{0}$ is found shifted few $\mathrm{mm}$ outward in the SOL with respect to the maximal heat flux location found with the edge diagnostics. 

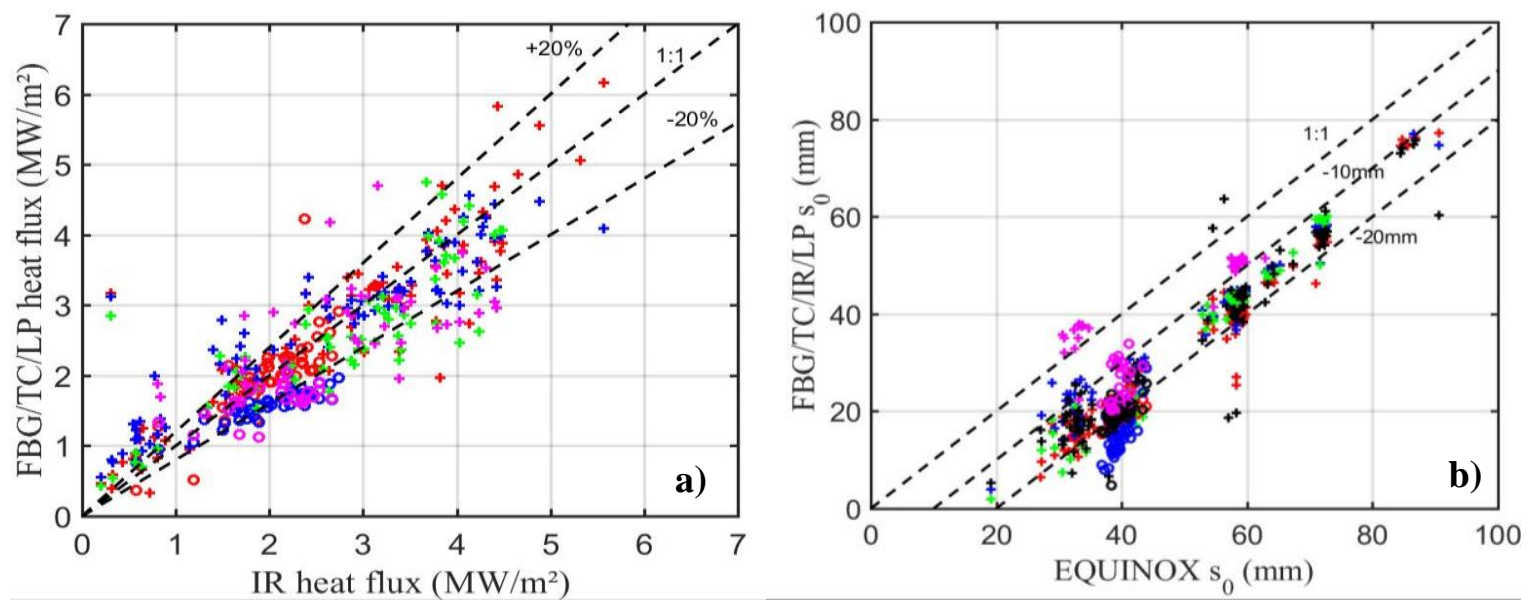

FIG. 2. a) Peak heat flux from FBG (red), TCQ6A (blue), TCQIA (green) and LP (magenta) compared to peak heatl flux from IR for (+) deuterium and (o) helium discharges. b) Strike point location 50 estimated from $F B G$ (red), TCQ6A (blue), TCQ1A (green), LP (magenta) and IR (black) compared to the reconstructed strike point location from NICE for deuterium (+) and helium (o) discharges.

Despite the good agreement on the heat flux intensity and location, differences are found on the heat flux decay length at the target estimated with the 4 diagnostics. Fig 3 compares the estimated $\lambda_{q}^{t}$ as function of the one the $\mathrm{TC}_{\mathrm{Q} 6 \mathrm{~A}}$ inversion. For the deuterium discharges (cross) 3 groups can be identified. A good agreement between $\mathrm{TC}_{\mathrm{Q} 6 \mathrm{~A}}$ and the $\mathrm{LP}$ measurements is found which is installed in the $\mathrm{PFC}$ next to the $\mathrm{TC}_{\mathrm{Q} 6 \mathrm{~A}}$ (see Fig $1 \mathrm{~b}$ )). Then the FBG and the $\mathrm{TC}_{\mathrm{Q} 1 \mathrm{~A}}$ are well in line together but $40 \%$ higher than the first group, these diagnostics are located $180^{\circ}$ away in the toroidal location and $60^{\circ}$ away from the first group, respectively. Finally, the $\lambda_{q}^{t}$ from the IR estimation is $40 \%$ lower compare to the values from $\mathrm{TC}_{\mathrm{Q} 6 \mathrm{~A}}$ which are on the same PFC. For the He discharges the LP and $\mathrm{TC}_{\mathrm{Q} 6 \mathrm{~A}}$ remains well in line, but the FBG estimation comes $30 \%$ lower and the IR estimation exhibit also higher discrepancy from 50 to $60 \%$ lower than the $\mathrm{LP}$ and $\mathrm{TC}_{\mathrm{Q} 6 \mathrm{~A}}$ estimations. To understand these discrepancies several studies are on-going. For the embedded measurement, as the WEST phase 2 will start in summer 2021 all the instrumented PFCs of the WEST phase 1 have been removed from the machine. An extensive post-mortem analysis will be performed to check the validity of the thermal measurement (time response, calibration etc.) as extensive numerical tests have been done to compare the inversion from TEDDY [11] and the embedded measurement in regard to the assumptions. For the IR, a post-mortem activity is also on-going to measure the PFC emissivity and confirm the observations made in the machine for the emissivity spatial distribution [13] due to impurities redeposition. Measurements of the emissivity evolution with the temperature is foreseen on the different areas (low and high emissivity) to take into account this variation in the IR processing performed in the TEDDY. This upgrade could contribute to the comparison especially for He discharges where long discharges have been performed with high surface temperatures reaching up to $1000{ }^{\circ} \mathrm{C}$. Then other approach is under development for the IR processing based on inverse method to have a better evaluation of the reflected light which could perturbate the IR inversion in the cold area [17].

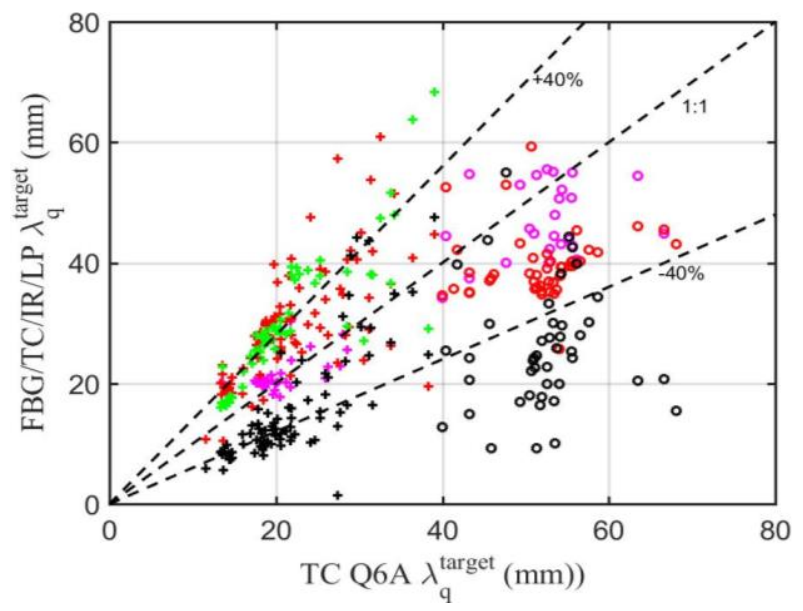


FIG. 3. Heat flux decay length at the target $\lambda_{q}^{t}$ from FBG (red), TCQIA (green), LP (magenta) and IR (black) compared $\lambda_{q}^{t}$ from $T C_{Q 6 A}$ for deuterium (+) and helium (o) discharges.

\section{HEAT LOADS OBSERVATIONS BASED ON EMBEDDED MEASUREMENTS}

In this section we extend the database to a total of 228 discharges with discharges from the two previous campaigns called C2 and C3 with 7 and 56 discharges, respectively. We focus on the peak heat flux evolution on the divertor through the campaigns as well as the inner/outer asymmetry based on observations made with FBG and TCs inversion as all the heat load diagnostics give equivalent value for the peak heat flux and absorbed energy by the PFC [7].

\subsection{Heat flux evolution over the campaigns}

Fig 4a) shows the deposited peak heat flux as function of the divertor power $\left(\mathrm{P}_{\mathrm{div}}=\mathrm{P}_{\mathrm{tot}}-\mathrm{P}_{\mathrm{rad}}\right)$ for the outer and inner side of the WEST divertor and the three consecutive campaigns. The values have been averaged over 1s during the stationary phase of each discharge. An important increase of the deposited peak heat flux versus $\mathrm{P}_{\text {div }}$ over the campaigns is observed. The increase is about 1.7 between the campaigns $\mathrm{C} 3$ and $\mathrm{C} 4$ on both side of the divertor and it is higher than the dispersion during a campaign due to the different magnetic configurations performed (mainly X-point height variation leading to a modification of the heat flux expansion on the target). The analysed C3 database is equivalent to the C4 database in terms of magnetic configuration, plasma current (mainly $500 \mathrm{kA}$ ), density, and LHCD power (up to 4.7 MW during C3 and 4.8 MW for C4). The target heat flux decay length $\lambda_{q}^{t}$ is also equivalent during the two campaigns and roughly linearly depends on the X-point height as illustrated in Fig 4b) with only outer $\lambda_{q}^{t}$ shown for $500 \mathrm{kA}$ discharges, excluding a potential reduction of the SOL width over the campaigns to explain the heat flux increase. One can note that the maximal deposited heat flux observed is about $6 \mathrm{MW} / \mathrm{m}^{2}$ for discharges with $4 \mathrm{MW}$ of $\mathrm{LH}$ power, radiated fraction of $45 \%$ and X-point height of $120 \mathrm{~mm}$ showing that the $10 \mathrm{MW} / \mathrm{m}^{2}$ could be achieved with about $7 \mathrm{MW}$ of additional power in this configuration in Lmode.
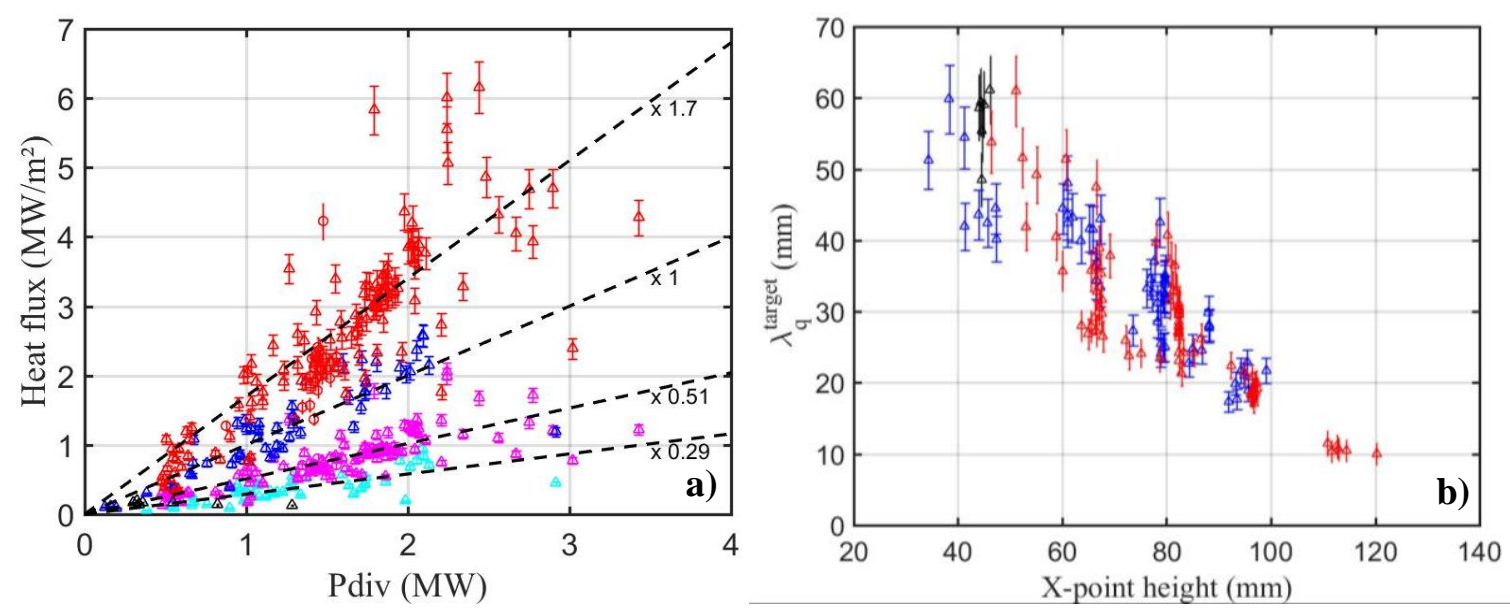

FIG. 4. a) Peak heat flux from embedded measurement (TC/FBG) as function of $P_{\text {div }}$ at the outer strike point (OSP) and Inner strike point (ISP) for C4 OSP (red), C3 OSP (blue), C2 OSP (black), C4 ISP (magenta) and C3 ISP (cyan) for deuterium ( $\triangle)$ and helium (o) discharges. $b$ ) Heat flux decay length at the target $\lambda_{q}^{t}$ as function of the X-point height for $C 4$ OSP (red), C3 OSP (blue) and C2 OSP (black).

The TC acquisition is performed in a continuous way throughout all days and nights. As the instrumented tiles are inertial graphite tiles without active cooling, the TC measurements in between discharges can be used to perform calorimetry study and determine the absorbed energy during a discharge. To do so, the method developed at JET for the energy balance study with TC has been applied for the WEST divertor PFC instrumented with TC [18]. First, the method has been validated on numerical data showing moderate errors of $5 \%$ and up to $10 \%$ when small time slice is considered for the analysis. Then the method has been applied on the 228 discharges previously analysed. The absorbed energy from the cooling phase has been compared to the absorbed energy determined from the inversion of the measurements during the discharge. The comparison has shown a good agreement 
between the two estimated energies with a discrepancy from 4 to $15 \%$ depending on the time slice available for the cooling phase study. Then the procedure has been applied to the whole WEST database for discharges with at least $4 \mathrm{MJ}$ of injected power, representing 1272 discharges over the campaigns C2, C3 and C4. Thanks to the 1.5 $\mathrm{mm}$ gap between the inner and outer PFCs the energy estimated by this method will only take into account the energy deposited on each side of the divertor. But the outer PFC is partially shadowed by the baffle intercepting the radiated power and a part of the SOL heat load depending on the distance between the last closed magnetics surface and the baffle (see Fig 1 a)).

Fig 5 a) and b) show the absorbed energy for the inner and outer PFCs of the sector Q6A instrumented with 4 TCs. For the inner side the campaigns $\mathrm{C} 3$ and $\mathrm{C} 4$ exhibit two slopes with a factor $0.38 \mathrm{~kJ} / \mathrm{MJ}$ and $0.57 \mathrm{~kJ} / \mathrm{MJ}$, respectively, showing an absorbed energy 1.5 times higher in $\mathrm{C} 4$ comparing to $\mathrm{C} 3$. This factor is slightly lower than the factor of 1.75 obtained in the Fig $4 a$ ), this is due to the fact that the absorbed energy $E_{\text {inner }}$ is the sum of the energy from the SOL deposition on the PFC, the radiated energy and the neutral loads. While the deposited heat flux in the Fig 4a) is only due to the SOL deposition. The Fig 5 a) shows also the equivalent behaviour of the radiated power during $\mathrm{C} 3$ and $\mathrm{C} 4$ deduced from the absorbed energy by the lower divertor during Upper Single Null (USN) discharges. The last feature from the $\mathrm{E}_{\text {inner }}$ evolution is the discharges outlined with the elliptical black dashed line. Some discharges with low radiated fraction are related to have been performed soon after a boronization and other exhibit strong MHD activity with crashes on the lower divertor inducing higher deposited energy. Finally, some discharges have a magnetic configuration with Rext $=2.93 \mathrm{~m}$ and a low X-point height inducing that the outer strike point is close to the gap and a part of the power of the outer leg is interacting with the inner side. Fig 5b) shows also clearly the increase of the deposited energy on the outer side between C3 and $\mathrm{C} 4$ with a factor of 1.6 or 2.2 depending on the magnetic configuration. These two factors can be explained by the reduction of the SOL falling on the baffle when the $\mathrm{R}_{\text {ext }}$ is lower due to the increase of the distance between the last closed magnetic surface and the baffle. Once again, the USN discharges show equivalent deposited energy for $\mathrm{C} 3$ and $\mathrm{C} 4$. Finally, the energy from the $\mathrm{C} 2$ campaign show the very low deposited heat load on the divertor during the campaign as already shown in Fig 4a).

The last diagnostic confirming the increase of the deposited heat load is the calorimetry from the upper divertor. The comparison of equivalent discharge from C3 and C4 have shown that in LSN configuration the water flowing in the upper divertor extract about $10 \%$ of the injected energy. During USN discharges in C3 this fraction increase to $20 \%$ due to the deposition of the SOL power and in C4 this value goes to $29 \%$ (with equivalent radiated fraction as shown in Fig 5) showing an equivalent increase as the one observed at the lower divertor in LSN configuration.
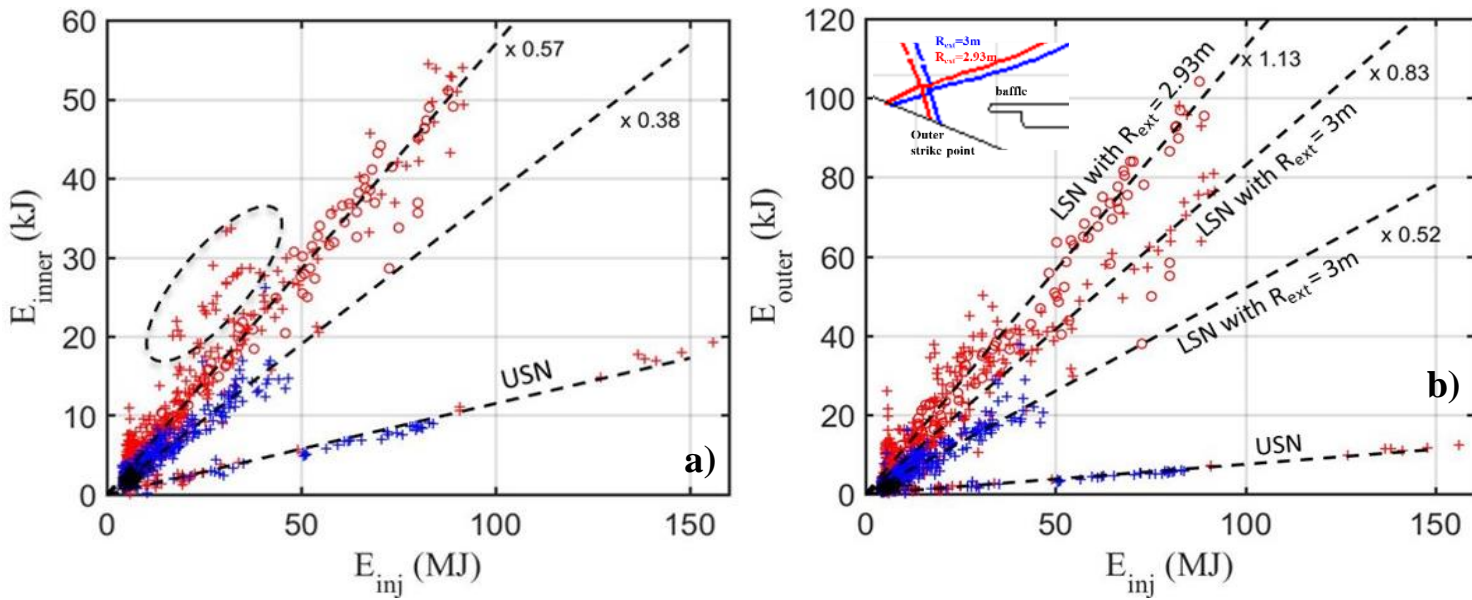

FIG. 5. Absorbed energy by the a) inner and b) outer PFCs instrumented with 4 TC as function of injected energy for C4 (red), C3 (blue) and C2 (black) for deuterium (+) and helium (o) discharges.

\subsection{Outer/Inner Asymmetries}

For both LSN and USN plasmas performed so far, WEST operates with forward toroidal field direction as in ITER $(B \times \nabla B$ drift direction towards the lower divertor). In this configuration the outer-inner heat load distribution is expected to be clearly asymmetric with higher heat load on the outer side $[19,20]$. This asymmetry can be expressed in terms of absorbed energy by the PFCs or heat fluxes (deposited on the PFC or parallel considering the optical projection assumption). Fig 6 a) compares the outer and inner peak parallel heat flux obtained from the 
projection of the deposited heat flux estimated with embedded measurement with the incident angle, varying from 2.2 to $4.2^{\circ}$, for the 228 discharges of the inversion database. Fig 6 a) shows an important asymmetry with outer heat flux 3 times higher than the inner leading to a ratio $3 / 4$ and $1 / 4$ for the heat load distribution for the outer and inner sides, respectively. As seen in the previous section this asymmetry is constant over the campaigns independently of the increase of the heat load reaching the divertor. No clear dependency has been found on this database with the edge safety factor $\mathrm{q}_{95}$, the density or the injected power, but the database is mainly composed by deuterium plasmas at $500 \mathrm{kA}$ and helium plasmas at $300 \mathrm{kA}$ with central density in the range of $3-4.10^{19} \mathrm{~m}^{-}$ 3 . This asymmetry is $15 \%$ higher when we consider the deposited heat flux corresponding to the $15 \%$ higher incident angle on the outer side.

Fig 6 b) compares the absorbed energies on the outer and inner side using the cooling phase method [18] to increase the database to 1272 discharges. Three slopes emerge corresponding mainly to the different magnetic configurations with different distance between the baffle and the last closed magnetic surface. The $2 / 3$ slope corresponds to the USN plasmas where only the radiated and neutral loads are deposited on the PFCs. One can note the $2 / 3$ slope is different to the surface ratio $S_{\text {outer }} / S_{\text {inner }}$ of the PFCs which is about 0.9 , this difference is explained by the baffle shadowing screening a part of the radiated an neutral loads as a part of the outer PFC is under the baffle. The two other slopes correspond to LSN plasmas performed with different radial location of the plasma, the 1.5 slope corresponds to the plasmas performed at $\mathrm{R}_{\mathrm{ext}}=3 \mathrm{~m}$ and the slope 1.9 to the plasma performed at $R_{\text {ext }}=2.93 \mathrm{~m}$. The energy asymmetry is also constant over the campaigns with equivalent slope for C3 and C4 showing no strong variation of the heat load asymmetry.
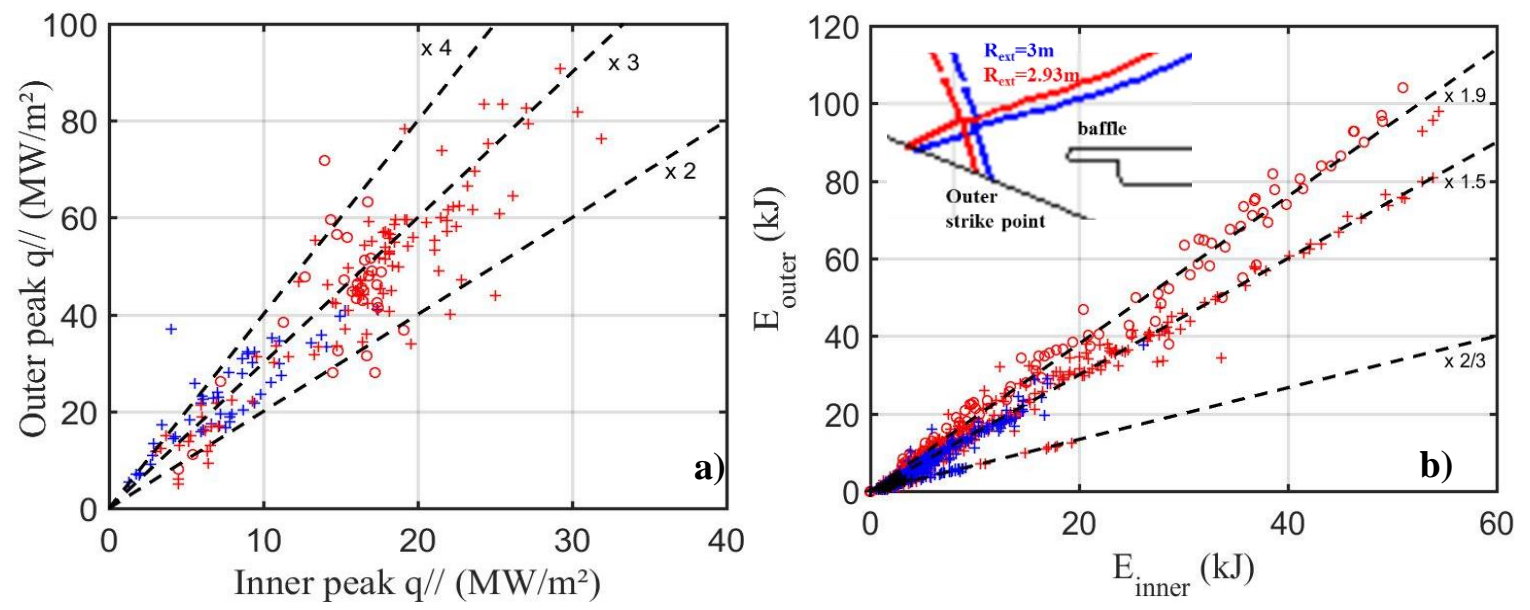

FIG. 6. a) Outer versus inner peak parallel heat flux for C4 (red), C3 (blue) and C2 (black) for deuterium (+) and helium (o) discharges. b) Outer versus inner absorbed energy C4 (red), C3 (blue) and C2 (black) for deuterium (+) and helium (o) discharges (based on TC measurements).

\section{CONCLUSION}

The discharge database of the first crosscheck analysis between IR and FBG heat flux estimation [4] has been extended from 114 discharges to 165 whilst three additional diagnostics has been introduced to the crosscheck analysis. The TC inversions from the 2 tiles instrumented with 4 TCs (Q6A and Q1A) have been added as well as the LP measurements (Q6A) for 63 discharges corresponding to the last part of the C4 campaign. This database includes attached discharges in L-mode, in Lower Single Null (LSN) plasma configuration with heating powers ranging from 1 to $8 \mathrm{MW}$ (with up to $4.8 \mathrm{MW}$ of lower hybrid current drive and up to $3.1 \mathrm{MW}$ of ion cyclotron resonance heating) with magnetic field $\mathrm{B}_{\mathrm{T}}$ from 3.5 to $3.7 \mathrm{~T}$ and plasma current $\mathrm{I}_{\mathrm{p}}$ from 300 to $700 \mathrm{kA}$ (corresponding to edge safety factor $\mathrm{q}_{95}$ from 7.8 to 3.2 respectively). The first observation is the good agreement of the peak heat flux $( \pm 20 \%)$ from the IR, the set of 3 embedded sensors and the LPs over a large variety of plasma scenario. This agreement remains during X-point height scan varying the magnetic flux expansion from about 2 to 6 at the target and moved radially the peak heat flux location over $6 \mathrm{~cm}$. However as depicted in [7] discrepancy is observed for the heat flux decay length $\lambda_{q}^{t}$ from the different diagnostics. The addition of the 3 new diagnostics shows 3 groups $\lambda_{q}^{t}$ values, the TC $\mathrm{T}_{\mathrm{Q} \mathrm{A}}$ and LP, installed in neighboring PFC, exhibit equivalent $\lambda_{q}^{t}$ values, the IR (looking at the same tile as $\left.\mathrm{TC}_{\mathrm{Q} 6 \mathrm{~A}}\right)$ has the lowest values $(-40 \%)$ and the $\mathrm{FBG}$ and $\mathrm{TC}_{\mathrm{Q} 1 \mathrm{~A}}$ have the highest values $(+40 \%)$. Strikingly the TC inversions performed with equivalent PFC versus ripple modulation (toroidally spaced by $60^{\circ}$ ) exhibit $40 \%$ variation on the $\lambda_{q}^{t}$ values. 
Thanks to the availability of the embedded measurements since the WEST start, the heat flux evolution over the campaigns shows clear increase with a factor about 1.7 between the campaign $\mathrm{C} 3$ and $\mathrm{C} 4$ on both strike point regions. The $\mathrm{C} 2$ campaign exhibit also very low heat flux lower than $0.2 \mathrm{MW} / \mathrm{m}^{2}$ despite $2.3 \mathrm{MW}$ of LHCD power. These increases cannot be attributed to a SOL width reduction as the heat flux decay length at the target remains equivalent through all the campaigns and scale mainly with the magnetic flux expansion through the variation of the X-point height as expected. The0 maximum heat flux observed on the outer strike point region is about 6 $\mathrm{MW} / \mathrm{m}^{2}$ with a total injected power of $4 \mathrm{MW}$ of $\mathrm{LHCD}$ power with a radiated fraction in a range of $50 \%$. These results are very encouraging and they exhibit the capability to reach $10 \mathrm{MW} / \mathrm{m}^{2}$ with about $7 \mathrm{MW}$ of additional power in L-mode plasma. The heat load distribution is clearly asymmetric with a factor 3/4 1/4 distribution for the parallel heat flux higher on the outer region as commonly observed in forward-B divertor configuration.

\section{ACKNOWLEDGEMENTS}

This work has been carried out thanks to the support of the A*MIDEX project ( ${ }^{\circ}$ ANR-11-IDEX-0001-02) funded by the "Investissements d'Avenir" French Government program, managed by the French National Research Agency (ANR).

This work has been carried out within the framework of the EUROfusion Consortium and has received funding from the Euratom research and training programme 2014-2018 and 2019-2020 under grant agreement No 633053. The views and opinions expressed herein do not necessarily reflect those of the European Commission.

\section{REFERENCES}

[1] C. Bourdelle et al, WEST Physics Basis, Nuclear Fusion 55 (2015) 063017.

[2] J. Bucalossi et al, this conference.

[3] Y. Corre et al, Review of Scientific Instruments 89, 063508 (2018); doi: 10.1063/1.5024514.

[4] X. Courtois et al, Full coverage infrared thermography diagnostic for WEST machine protection, Fusion Engineering and Design 146 (2019) 2015-2020.

[5] R. Dejarnac et al, Flush-mounted Langmuir probes in the WEST tokamak divertor, Fusion Engineering and Design 163 (2021) 112120.

[6] J. Gaspar et al, First heat flux estimation in the lower divertor of WEST with embedded thermal measurements, Fusion Engineering and Design 146 (2019) 757-760.

[7] N. Fedorczak et al, Cross diagnostics measurements of heat load profiles on the lower tungsten divertor of WEST in Lmode experiments, Nuclear Materials and Energy 27 (2021) 100961.

[8] M. Missirlian et al, Fusion Engineering and Design 89 (2014) 1048-53.

[9] M. Firdaouss et al, Fusion Engineering and Design 98-99 (2015) 1294-8.

[10] J. Gaspar et al, Journal of physics: Conference Series 745 (2016).

[11] N. Fedorczak et al, Infra-red thermography estimate of deposited heat load dynamics on the lower tungsten divertor of WEST, Physica Scripta, (2020), T171

[12] M-H. Aumeunier et al, Infrared thermography in metallic environments of WEST and ASDEX Upgrade, Nuclear Materials and Energy 26 (2021) 100879

[13] J. Gaspar et al, In-situ assessment of the emissivity of tungsten plasma facing components of the WEST tokamak, Nuclear Materials and Energy 25 (2020) 100851

[14] J. Gaspar et al, Emissivity measurement of tungsten plasma facing components of the WEST tokamak, Fusion Engineering and Design 149 (2019) 111328.

[15] A. Scarabosio et al, Outer target heat fluxes and power decay length scaling in L-mode plasmas at JET and AUG, Journal of Nuclear Materials 438 (2013) S426-S430

[16] F. Blaise et al, Nuclear Fusion, 58 (10) (2018), Article 106032

[17] C. Talatizi et al, Inverse radiation problem with infrared images to monitor plasma-facing components temperature in metallic fusion devices, Fusion Engineering and Design 159 (2020) 111867

[18] G.F. Matthews et al, Energy balance in JET, Nuclear Materials and Energy 12 (2017) 227-233

[19] R.A. Pitts et al, Edge and divertor physics with reversed toroidal field in JET, Journal of Nuclear Materials 337-339 (2005) 146-153

[20] R. Maurizio et al, Divertor power load studies for attached L-mode Single-Null plasmas in TCV, Nuclear Fusion 58 (2018) 016052 